\title{
Outcome of the use of bakri balloon in obstetric hemorrhage
}

\author{
Abstract \\ Objective: To present the results obtained by using the Bakri Balloon to obstetric control \\ hemorrhage. \\ Material and method: Prospective, observational study within two inpatient medical care \\ units since January 1 to December 31 2016. Twenty patients with post-partum and trans \\ cesarean hemorrhage. All of them were applied the Bakri Balloon because of failure to \\ respond to uterotonic drug therapy. The following were analyzed: \\ a. Clinical data \\ b. Amount of bleeding before and after the balloon \\ c. Amount of postpartum or trans cesarean bleeding \\ d. Time between diagnosis and insertion, insufflation time and volume supplied \\ e. Hemoglobin levels and coagulation tests results initially, post- hemorrhage and post \\ insertion \\ f. Use of and amount of haemo components ministered \\ g. The time use balloons, success, and complications
}

Results: The amount of bleeding after insertion, both in postpartum and trans cesarean was reduced and there was an adequate response in hemoglobin levels. The average time between hemorrhage diagnosis and balloon insertion was thirty minutes; average insufflation time, five minutes, and average volume supplied $400 \mathrm{~mL}$. Balloon's average use time, 29.5 hours. In $95 \%$ of the cases there was a positive response for hemorrhage control, with no complications derived from use.

Conclusions: The Bakri Balloon proved to be a useful, quick and complication -free therapy for controlling obstetric hemorrhage.

Keywords: obstetric hemorrhage, Bakri Balloon
Volume 9 Issue 4 - 2018

\author{
Eduardo de la Luna and Olsen,' Blanca \\ Carranza Sánchez, ${ }^{2}$ Laura Nava López, ${ }^{2}$ Ana \\ Rosa Andrade del Toro, ${ }^{2}$ Sandra Arellano \\ Cabrera, ${ }^{2}$ Jorge Rodríguez Avalos, ${ }^{3}$ Marco \\ Aurelio Vences Avilés ${ }^{4}$ \\ 'Gynecology and Obstetrics, Mexico \\ ${ }^{2}$ Gynecology and Obstetrics, Gynecology and Obstetrics \\ Service, Silao General Hospital, Mexico \\ ${ }^{3}$ Gynecology and Obstetrics, Head of Reproductive Health, \\ General Hospital, Mexico \\ ${ }^{4}$ Medical Epidemiologist, In charge of the Epidemiology Service \\ of the Silao General Hospital, Mexico
}

Correspondence: Dr. Eduardo de la Luna and Olsen, Gynecology and Obstetrics, Cerro del Erizo \# 39, Col. Valenciana, CP 36240. Guanajuato, Gto, Mexico, Tel (0I) 47373 38068,Email delalunayolsen@gmail.com

Received: May 16, 2018 | Published: August 02, 2018

\section{Background}

Obstetric hemorrhage has increased its frequency ${ }^{1-3}$ for different reasons, among which are the increase in cesarean section and inadequate use of uterotonics, among others. ${ }^{4-6}$ It occupies the second cause of maternal deaths in our country and in some States, the first. ${ }^{7-9}$ Several strategies have been carried out for its reduction, without obtaining the expected results. ${ }^{3,8,9}$ Several decades ago the most practiced surgical treatment, once failed ls medical measures, was obstetric hysterectomy, which besides being a limiting fertility procedure in many patients, and was not without many complications. ${ }^{10,11}$ Nowadays, this behavior is increasingly questioned as the first therapeutic procedure and even in many countries it is the subject of medical litigation. ${ }^{12,13}$ Others, though effective, surgical techniques such as hypogastric artery ligation or devascularization of the uterine vessels require significant medical training and good experience, both often absent in our hospital means. ${ }^{14-16}$ The advent of procedures considered more conservative, such as the application of the Bakri intrauterine balloon, which requires a low and rapid learning curve, has demonstrated its usefulness for the effective control of obstetric hemorrhage and with minimal complications. ${ }^{17,18} \mathrm{Up}$ to this date there are multiple reports on their use. ${ }^{9,20,21}$

The objective of this report is to present the results obtained in two hospitals with the use of Bakri's intrauterine balloon to control obstetric hemorrhage both in the postpartum and in the trans-cesarean, its relation to the amount of hemorrhage and hemoglobin levels before and after its application.

\section{Material and method}

Prospective, longitudinal study performed in two hospital units: Hospital Silao General of the Ministry of Health of the State of Guanajuato and General Hospital Los Reyes, Secretary of Health of the State of Michoacan, in a span of 1. From January to December 31, 2016, of consecutive cases that went to the medical units in the period indicated. We included 20 patients who presented both postpartum and trans cesarean hemorrhage. Hemorrhage was considered from $500 \mathrm{~mL}^{22}$ and / or when the patient presented data on hypovolemia, characterized by hypotension (equal to or less than 90/60 for systolic / diastolic), tachycardia (equal to or greater than 100). 1/min), tachypnea (equal to or greater than $20 \mathrm{r} / \mathrm{min}$ ), neurological changes (confusion, restlessness, decreased alertness), decreased urine output (less than $20 \mathrm{~mL} /$ hour ) and decreased capillary refill., ${ }^{4,22}$ The amount of bleeding was calculated in two ways: $1^{\text {st }}$ ) by gravimetry, weighing with gauze and compresses during the procedures and $2^{\text {nd }}$ ) with collection bag type Brass $-\mathrm{V}$, Calibrated obstetric drape $\left(\right.$ Maternova $\left.^{\mathrm{TM}}\right)$. All the patients were initially treated with uterotonics. First choice oxytocin was used at a rate of $10 \mathrm{U} \mathrm{IV}$, diluted in $10 \mathrm{ml}$ of Hartman solution 
passing slowly (1min), if no response was obtained; Carbetocin was continued $^{\mathrm{TM}}$ (Lab. Ferring) $100 \mathrm{mcgs}, 1 \mathrm{ml}$ IV in 1 minute. In all patients the hemoglobin admission unit determined, a post-hemorrhagic event twenty - four hours time after use with the ball or before removal thereof. . $^{23,24}$

All patients without response to medical treatment were given an intrauterine Bakri balloon (Cook Medical, Bloomington, IN. USA, Demesa, Mexico City) (Figure 1).

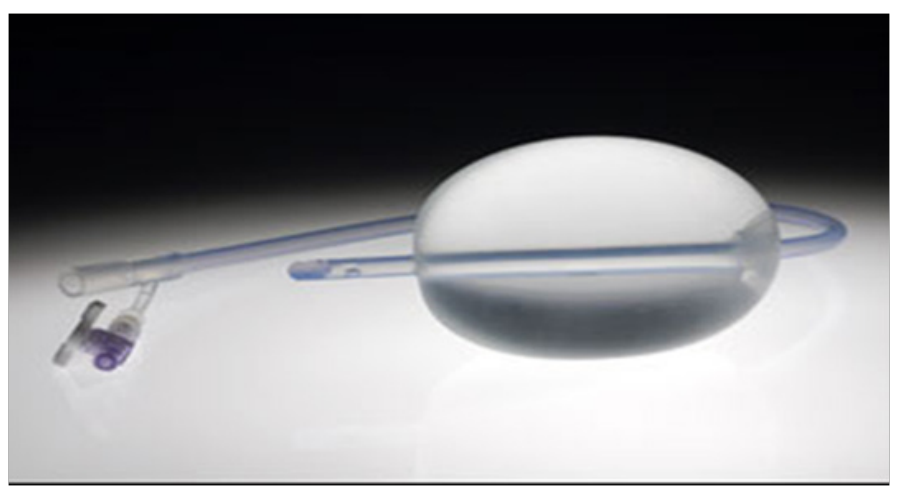

Figure I Bakri ball.

The application of the balloon in postpartum cases was performed with the following technique:

Visualization of the cervix through vaginal valves, asepsis and antisepsis of the region, clamping of both cervical lips. The balloon was applied by guide with ring clamp to the uterine cavity. The balloon was filled with a $60 \mathrm{~mL}$ syringe, with sterile, warm saline. The amount to be infused depended on the response to control the bleeding, without exceeding $500 \mathrm{~mL}$ total. The filling speed was recorded. The correct placement of the balloon was corroborated, clinically in the initial phase and a gauze plug was placed in the bottom of the bag to favor the anterior position towards the pubis of the cervix and thus avoid the possible externalization of the balloon. The insufflation catheter was fixed to the thigh of the patient and connected to a collection bag to obtain a strict control of the amount of bleeding. At the end of the procedure, the correct placement of the balloon by abdominal ultrasound was corroborated.

In cases of trans cesareal balloon application, the technique was performed through hysterotomy, directing the balloon to the fund us of the uterus and the catheter for filling was passed trans cervical until vagina where a helper led him to the outside and proceeded to fill it with the same technique and quantity of solution required and described for postpartum cases. The hysterorraphy was performed with the usual technique. At the end of the procedure, its proper placement by abdominal ultrasound was also corroborated. In all cases the ball was placed by different doctors Gineco -Obstetras with training in the procedure.

$\mathrm{L}$ as patients remained completely still during the time the ball had been prescribed prophylactic antibiotic, acinus Ciproflox $1 \mathrm{~g}$ intra venous (Basic table and catalog of medications, 2014. key 1937.00). All patients had hemoglobin determination and coagulation tests on admission to the care units. In to dorslors cases determination of hemoglobin and coagulation tests was performed one hour after the hemorrhage and 24hours after treatment with blood components or before removing or $\mathrm{d}$ the ball.
$\mathrm{T}$ he result is divided into:

Positive response: Control of bleeding no greater than $150-200 \mathrm{~mL}$ March 2 in 24hours and recovered ban signs of hypovolemia. In these cases the balloon was removed between 24 to 48 hours

Negative response: When control of bleeding was not obtained and hypovolemia data persisted. In these cases, another therapeutic measure was taken with the immediate removal of the balloon.

$\mathrm{S}$ and performed the following analysis:

i. Semanate gestation, gynecology- obstetric history, diagnosis of the cause of bleeding and medical treatment prior to application of the ball.

ii. The amount of bleeding before and after the application of the balloon.

iii. The amount of bleeding between the cases of delivery and cesarean, before and after the placement of the balloon in the same groups.

iv. The time between diagnosis and the affixing of the balloon, filling time and volume delivered.

v. Hemoglobin levels and coagulation tests 1 entrance to unit, the posterior bleeding hour and 24 hours after of treatment with blood components, at the moment of removal of the balloon.

vi. The cases that required the use of heme components and the amount of them used during the event.

vii. The percentage of success or failure of the procedure and time of use of the ball. Likewise complications analyzed by the use of the ball and if present arons cases of maternal death.

Descriptive statistics of numerical (mean and standard deviation) and categorical (proportions) data were used. Due to the small size of the sample, since the distribution of the data was not normal, nonparametric statistics were used. For the comparison of numerical variables before and after the use of the Bakri balloon in patients with uterine bleeding, the Wilcoxon test of the signed ranges was used. To compare numerical data of the patients with cesarean section and delivery, the amount of bleeding comparing them and the hemoglobin values at the different times indicated, the Mann Whitney U test was used. A value of $\mathrm{p}<0.05$ was considered statistically significant. For the analysis of the data, the IBM SPSS version 22 statistical package was used

\section{Results}

Twenty patients were treated during the study period. According to the seven points poured into the material and method, the following results were obtained:

a. The weeks of gestation, gynecological-obstetric history, cause of hemorrhage and the treatment instituted before the application of the Bakri balloon, appear and $\mathrm{n}$ Table 1.

b. The mean and standard deviation for age and weeks of gestation were respectively 24.6 (7.0) and 38.2 (2.7).

c. In 15 patients (75\%) labor occurred and in $5(25 \%)$ the resolution of the pregnancy was by caesarean section.

d. The amount of bleeding before and after Bakri balloon application 
was $1570+687 \mathrm{~mL}$ and $130.7+112 \mathrm{~mL}$, respectively $(Z=-3,924$ $\mathrm{p}=0.000087$ ). The total amount of bleeding during the event, the time between diagnosis and placement of the balloon, time of filling, amount of solution for filling and time of permanence of the balloon appear in Table 2 .

e. The amount of bleeding between the cases of delivery and cesarean section before the application of the Bakri balloon was $1407+672 \mathrm{~mL}$ and $2060+513 \mathrm{~mL}(\mathrm{Z}=-2.08, \mathrm{p}=0.037)$. The amount of bleeding between the same groups after balloon placement was $128+123 \mathrm{~mL}$ and $140+82.1 \mathrm{~mL}(\mathrm{Z}=-3.189$, p $=0.001$ ).

f. The average time between diagnosis and Bakri balloon placement was 30 minutes (5-120minutes). This was the time between which the bleeding was presented, the medical treatment was performed, the result was expected and the balloon application was decided. Once he proceeded to the application of the balloon into the uterine cavity e 1 time it was made and 1 filling averaged 5 minutes (3-10minutes). The average amount of volume administered was $400 \mathrm{~mL}(250-500 \mathrm{~mL})$ Table 2.

g. Average levels of hemoglobin at admission to the unit, one postadult hour and twenty - four hours after the treatment with blood components and before the balloon removal, were $11.8 \mathrm{~g} / \mathrm{dL}$, $8.1 \mathrm{~g} / \mathrm{dL}$ and $9.6 \mathrm{~g} / \mathrm{dL}$, respectively, with significant differences in the first two cases (on admission and post- graduation ) with $\mathrm{Z}=-3.92 ; \mathrm{p}=0.00008$. There was also a difference between hemoglobin at admission and post - treatment with hemo components before the removal of the balloon, with $Z=-3.03$; $\mathrm{p}=0.002$ (Table 3$)$.

h. In 19 patients (95\%) the coagulation tests in the same periods of time were normal. Only in one case $(5 \%$, patient 4$)$ the coagulation times were prolonged in the immediate post- acute (Table 4)

i. In $85 \%$ of the cases the use of a globular package with an average of 2.7 units was required, with a range of 1 to 6 units. In case number 4,8 units of fresh plasma and 6 platelet concentrates were required.

j. In 19 patients (95\%) a favorable response was obtained with the application of the Bakri balloon. In none of these cases was required the application of a second balloon during the time of use, nor after the withdrawal of the same. The mean and standard deviation of the time of use of the balloon was 29.5hours with an SD of 13.5 hours

Table I Clinical characteristics. Diagnosis and initial treatment

\begin{tabular}{|c|c|c|c|c|c|}
\hline No patients & Age & AUG & $\begin{array}{l}\text { Weeks } \\
\text { Gestation }\end{array}$ & Diagnosis & Pretreatment ball Bakri \\
\hline I & 21 & $\mathrm{GI}, \mathrm{Cl}$ & 36 & Previous placenta & $\mathrm{Ox}, \mathrm{Mi}, \mathrm{Ca}$ \\
\hline 2 & 21 & $\mathrm{G} 2, \mathrm{C} 2$ & 40.2 & $\begin{array}{l}\text { TP Extended } \\
\text { I8 hours }\end{array}$ & $\mathrm{Ox}, \mathrm{Mi}, \mathrm{Ca}$ \\
\hline 3 & 18 & GI,PI & 38 & Uterine hypotonia & $\mathrm{Ox}, \mathrm{Ca}$ \\
\hline 4 & 19 & $\mathrm{G} 2, \mathrm{P} 2$ & 37 & Uterine hypotonia & $\mathrm{Ox}, \mathrm{Mi}, \mathrm{Ca}$ \\
\hline 5 & 21 & $\mathrm{G} 2, \mathrm{PI}, \mathrm{Cl}$ & 40 & Uterine hypotonia & $\mathrm{Ox}, \mathrm{Mi}, \mathrm{Ca}$ \\
\hline 6 & 20 & $\mathrm{G} 2, \mathrm{P} 2$ & 38.5 & Uterine hypotonia & $\mathrm{Ox}, \mathrm{Mii}, \mathrm{Ca}$ \\
\hline 7 & 24 & G3, P3 & $4 I$ & Uterine hypotonia & $\mathrm{Ox}, \mathrm{Mi}, \mathrm{Ca}$ \\
\hline 8 & 17 & $\mathrm{G} 2, \mathrm{P} 2$ & 40 & Uterine hypotonia & $\mathrm{Ox}, \mathrm{Mi}, \mathrm{Ca}$ \\
\hline 9 & 32 & $\mathrm{G} 3, \mathrm{C} 2, \mathrm{Al}$ & 39.1 & Previous placenta & $\mathrm{Ox}, \mathrm{Mi}, \mathrm{Ca}$ \\
\hline 10 & 2.3 & $\mathrm{G} 3, \mathrm{PI}, \mathrm{Cl}, \mathrm{Al}$ & 32.6 & RPM. Prolonged TP I 6 hours & $\mathrm{Ox}, \mathrm{Ca}$ \\
\hline II & 19 & GI,PI & 38.6 & Prolonged TP I 5 hrs. macrosomia & $\mathrm{Ox}, \mathrm{Mi}, \mathrm{Ca}$ \\
\hline 12 & 3.4 & $\mathrm{G} 5, \mathrm{P} 4, \mathrm{Al}$ & 39.1 & Uterine hypotonia & $\mathrm{Ox}, \mathrm{Mi}, \mathrm{Ca}$ \\
\hline 13 & 42 & G6, P5,Al & 30 & Previous placenta & Ox, Mi, C \\
\hline 14 & 35 & G4, P4 & 39.6 & $\begin{array}{l}\text { Fortuitous birth } \\
\text { Uterine hypotonia }\end{array}$ & $\mathrm{Ox}, \mathrm{Mi}, \mathrm{Ca}$ \\
\hline 15 & 2.3 & $\mathrm{G} 2, \mathrm{PI}, \mathrm{Cl}$ & 39.6 & severe pre-eclampsia & $\mathrm{Ox}, \mathrm{Mi}, \mathrm{Ca}$ \\
\hline 16 & 32 & GI,PI & 39.4 & severe pre-eclampsia & $\mathrm{Ox}, \mathrm{Mi}, \mathrm{Ca}$ \\
\hline 17 & 18 & GI,PI & 41.3 & $\begin{array}{l}\text { Prolonged TP I } 9 \text { hrs } \\
\text { Uterine hypotonia }\end{array}$ & $\mathrm{Ox}, \mathrm{Mi}, \mathrm{Ca}$ \\
\hline 18 & 20 & GI,PI & 39.4 & Uterine hypotonia & $\mathrm{Ox}, \mathrm{Mi}, \mathrm{Ca}$ \\
\hline 19 & 22 & $\mathrm{G} 2, \mathrm{PI}, \mathrm{Al}$ & 39 & Uterine hypotonia & $\mathrm{Ox}, \mathrm{Mi}$ \\
\hline 20 & 31 & $\mathrm{G} 2, \mathrm{P} 2$ & 36 & RPM, prolonged PT I 7 hours & My, Ca \\
\hline
\end{tabular}

G, Gesta; P, Child birth; C, Cesarean;A, Abortion;TP, Labor; RPM, premature rupture of membranes; Ox, Oxytocin; Mi, Misoprostol; Ca, Carbetocin 
Table 2 Amount of bleeding, time between diagnosis and placement of the balloon, filling time, amount of solution used and dwell time

\begin{tabular}{|c|c|c|c|c|c|}
\hline No. Patient & $\begin{array}{l}\text { Total amount of } \\
\text { bleeding }(\mathrm{mL})\end{array}$ & $\begin{array}{l}\text { Time between diagnosis } \\
\text { and placement (min) }\end{array}$ & $\begin{array}{l}\text { Time of } \\
\text { filling }(\mathrm{min})\end{array}$ & $\begin{array}{l}\text { Amount of } \\
\text { soloution used } \\
(\mathrm{mL})\end{array}$ & $\begin{array}{l}\text { Time of } \\
\text { permanence } \\
\text { (hours) }\end{array}$ \\
\hline I & 2300 & 20 & 5 & 300 & 48 \\
\hline 2 & 1800 & 20 & 5 & 400 & 24 \\
\hline 3 & 1200 & 15 & 6 & 500 & 48 \\
\hline 4 & 3500 & 5 & 7 & 500 & 30 \\
\hline 5 & 1200 & 5 & 5 & 450 & 26 \\
\hline 6 & 1200 & 10 & 5 & 500 & 24 \\
\hline 7 & 900 & 5 & 5 & 350 & 48 \\
\hline 8 & 1800 & 20 & 5 & 340 & 24 \\
\hline 9 & 2300 & 5 & 5 & 500 & 48 \\
\hline 10 & 1300 & 5 & 4 & 400 & 24 \\
\hline II & 1000 & 5 & 5 & 500 & 24 \\
\hline 12 & 800 & 20 & 5 & 300 & 24 \\
\hline 13 & 2600 & 5 & 5 & 300 & 48 \\
\hline 14 & 1000 & 40 & 10 & 350 & 24 \\
\hline 15 & 2000 & 5 & 5 & 500 & 24 \\
\hline 16 & 1500 & 5 & 5 & 400 & 24 \\
\hline 17 & 1500 & 5 & 3 & 300 & 24 \\
\hline 18 & 1500 & 5 & 5 & 500 & 48 \\
\hline 19 & 1000 & 5 & 5 & 250 & 24 \\
\hline 20 & 1000 & 20 & 5 & 350 & 24 \\
\hline
\end{tabular}

* I) By gravimetry and 2) with collection bag Brass-V, Calibrated obstetric drape (Maternova TM) type.

Table 3 Amount of bleeding between cases of delivery and cesarean section. Before and after the application of the ball.

\begin{tabular}{llll}
\hline \multicolumn{2}{l}{ Bleeding before application of the ball * } & \multicolumn{3}{l}{ Bleeding after the application of the ball ** } \\
\hline Postpartum $\mathrm{mL}$ & Postpartum $\mathrm{mL}$ & After cesarean section $\mathrm{mL}$ & Cesarean section $\mathrm{mL}$ \\
$1407 \pm 672$ & $2060 \pm 513$ & $128 \pm 123$ & $140 \pm 82.1$ \\
\hline
\end{tabular}

$* \mathrm{p}=0.03 * * \mathrm{p}=0.001$

Table 4 Mean levels of hemoglobin on admission, one hour post- graduated and later to treatment with blood components and removal of the balloon

\begin{tabular}{lll}
\hline Hemoglobin to the Entrance g/dL* & Hemoglobin I hour Postsangrado g/dL* & Post- treatment hemoglobin g/dL** \\
\hline II.8 & 8.1 & 9.6
\end{tabular}

$$
* p=0.008 * * p=0.002
$$

In only one case (5\%), a positive response with the ball was not obtained. This patient presented a quantified bleeding in $3000 \mathrm{~mL}$, secondary to a uterine hypotonia. After the placement of the balloon at 30 minutes, the loss was $500 \mathrm{~mL}$, so the balloon was removed. The patient was transferred to intensive care, where the presence of coagulopathy due to consumption was corroborated. After volume restitution, fresh plasma and platelet concentrate with improvement in coagulation times, total abdominal hysterectomy was performed. There was no maternal death in the 20 cases studied.
There were no complications in the 19 patients who successfully used the Bakri balloon.

\section{Discussion}

The successes of Bakri's balloon in obstetric hemorrhage range from $100 \% 18,24$ to $80 \% .^{25}$ The variation in their results may depend on the cause of the bleeding, which is multiple. ${ }^{18,25-27}$ In this report predominated uterine hypotonia first cause and prolonged labor as second causes that seem to have a better response with the use of intrauterine balls. ${ }^{28,29}$ In both cases apparently the pathophysiology 
may be due to difficulty of the muscle fiber to occlude the uterine vessels in the immediate postpartum period. ${ }^{28,30}$ Bakri's balloon, by producing a hydrostatic effect on the vessels and occluding them, favors its haemostasis ${ }^{17,18,28}$ as well as activating hemostatic mechanisms and favoring the formation of a stable clot. ${ }^{31}$ Its use in other pathologies, such as placental accreta, reduces its effect. ${ }^{26,32}$

One issue discussed with its use is the amount of solution needed to fill the balloon. ${ }^{24}$ In our setting, Ortega-Vadillo correlated the volume to be infused with gestational age and the weight of the newborn, with good results, $94.2 \%$ of success. ${ }^{32}$ In our report the criterion for the amount of the filling was the cessation of bleeding, in quantities that were 250 to $500 \mathrm{cc}$, with an average of $400 \mathrm{cc}$ and we observed similar results. Therefore, we consider that any of these methods for filling the balloon provides similar results.

There are currently no reports in the literature that correlate the use of the Bakri balloon in cases of delivery and caesarean section, before and after its application in relation to hemoglobin levels, also before and after its use. In our report we found a statistically significant difference with the use of the balloon, in both cases. Therefore, we cannot compare our results with other studies. More studies are required comparing these variables. ${ }^{33}$

In the present report, there was no complication with the use of the ball. Some authors have reported accidents such as inadvertent uterine rupture, perforation 33 or spontaneous expulsion. ${ }^{34}$ The use of tamponade in the vaginal fund us to elevate the cervix towards the retro pubis, the practice of ultrasound to corroborate its adequate position and to keep the patient in absolute rest during the time of use, seem to be favorable measures to avoid this type of complications.

The success of the Bakri balloon in our report, $95 \%$, is similar to multiple studies already reported. . $^{18,20,21,24,32}$ Its ease of application, being a conservative, simple procedure with a fast and easily replicable learning curve make it suitable for the control of obstetric hemorrhage. In our report, the average time for its application was 5 minutes, a time that is not observed with other procedures that are equally effective, but more complex.

\section{Conclusion}

Bakri's balloon showed a favorable response for its use in obstetric hemorrhage. An adequate control of it is obtained, observing a significant decrease in the amount of bleeding, both in postpartum and trans cesarean cases, recovering the hemoglobin values before and after its use. Its level of security is adequate, easy to apply and with simple training. It has a successful result rate, in this report of $95 \%$, very similar to other reports in the literature.

\section{Acknowledgments}

None.

\section{Conflicts of interest}

The author declares that they do not have any conflicts of interest.

\section{References}

1. WHO. Maternal Mortality Consulted. World Health Organization; 2014.

2. SSA. Directorate General of Health Information (DGIS). Ministry of Health; 2014.
3. Say L, Chau D, Genill A, et al. Global Causes of Maternal Death: A WHO Systematic Analysis. Lancet Glob Health. 2014;2(6):e323-e333.

4. Diagnosis and treatment of obstetric hemorrhage in the second half of pregnancy and immediate puerperium. Mexico: Secretary of Health; 2009.

5. American College of Obstetricians and Gynecologists. ACOG Practice Bulletin. Clinical management guidelines for obstetrician-gynecologists number 76, October 2006: postpartum hemorrhage. Obstet Gynecol. 2006;108(4):1039-47.

6. Koczmarczyk M, P Sporen, Terry P, et al. Risk Cnottingius factors for uterine rupture and neonatal consequences of uterine rupture: a population based study of successive pregnancy in Sweden. Br J Obstet Gynecol. 2007;114:1208-14.

7. Observatory of Maternal Mortality. Indicators of maternal mortality. 2014.

8. Freyermuth G, Luna M. Maternal death and avoidable deaths in excess. Methodological proposal to evaluate public health policy. International Journal of Statistics and Geography. 2014;5(3)

9. Health. 2014.

10. Engelsen I, Albechtsen S, Iversen O. Peripartum hysterectomy. Incidence and maternal morbidity. Acta Obstet Gynecol. 2010;80(5):409-12.

11. Yamamoto H, Sogae S, Nishikawa S, et al. Emergency postpartum hysterectomy in obstetric practice. Obstet Gynecol. 2007;26(5):341-5.

12. Uribe R. Obstetric Hysterectomy. Critical judgement. Cir Ciruj. 2005;49: 207-13.

13. Committee on Obstetric Practice. Commmitte opinion. 529: Placenta accreta. Obstet Gynecol. 2012;120(1):2007-11.

14. Sentilhes L, Ambroselli C, Kagem G, et al. Maternal outcome after conservative treatment of placenta accreta. Obstet Gynecol. 2010;115(3):526-534.

15. O'Leary JL. Uterine artery ligation in the control postcesarean hemorrhage. J Reprod Med. 1995;40(3):189-93.

16. AbdRabbo SA. Stepwise uterine devascularization: A novel technique for management of uncontrollable postpartum hemorrhage with preservation of the uterus. Am J Obstet Gynecol. 1994;171(3):694-700.

17. Bakri YN. Uterine tamponade-drain for hemorrhage secondary to placenta previa- accreta. Int J Obstet Gynecol. 1992;37(4):302-303.

18. Bakri YN, Amri A, Abdul Jabbae F. Tamponade-ballon for obstetrical bleeding. Int J Obstet. 2001;74(2):139-42.

19. Gizzo S, Saccardi C, Patrelli TS, et al. Bakri ballon in vaginal-perineal hematomas complicating vaginal delivery to new therapeutic approach. J Low Genit Tract Dis. 2013;17(2):125-8.

20. Aibar L, Aguilar MT, Ports A, et al. Bakri ballon for the management of postpartum hemorrhage (Report). Acta Obstet Gynecol Scand. 2013;92:465-67.

21. Gronwall M, Tokkanen M, Tollberg E, et al. Use of Bakri ballon tamponade in the treatment of postpartum hemorrhage: a series of 50 cases form tertiary teaching hospital. Acta Obstet Gynecol Scand. 2013;92(4):433-38.

22. WHO recommendations for the prevention and treatment of postpartum hemorrhage. WHO; 2012:8-12.

23. Casella CA, Gomez UG, Meidana DJ. Normal puerperio. Postgraduate Magazine. Catedra VIa Medicine. 2000;100:2-6. 
24. Patacchiola F, D'Alfonso A, Di Fonso A, et al. Intrauterine balloon tamponade as management of postpartum haemorrhage and prevention of haemorrhage the related low lying placenta. Clin Exp Obstet Gynecol. 2012;39(4):498-99.

25. Vitthala S, Tsoumpou I, Kanjun A, et al. Use of Bakri ballon in postpartum hemorrhage: a series of 15 cases. Aust NZ J Obstet Gynecol. 2009;49(2):191-4.

26. Dabelea V, Schultze PM, McDuffie S. Intrauterine ballon tamponade in the management of postpartum hemorrhage. Am J Perinatol. 2007;24(6):359-64.

27. Kumru P, Demirci O, Erdogdu E, et al. The Bakri ballon for the management of poatpartum hemorrhage in cases with placenta previa. Eur J Obstet Gynecol Reprod Biol. 2013;167(2):167-70.

28. Georgiou C. Ballon tamponade in the management of pospartum haemorrhage: a review. BJOG. 2009;116(6):748-57.

29. Vintejoux E, Ulrich D, Mousty E, et al. Success factors for Bakri ballon usage secondary to uterine atony: a retrospective, multricentre study. Aust NZJ Obstet Gynaecol. 2015;55(6):572-7.
30. Abdul- Kadir R, McLintok C, Duclay AS, et al. Evaluation and management of postpartum hemorrhage: consensus from an international expert panel. Transfusion. 2014;54(7):1756-68.

31. Georgiou C. Intraluminal pressure readings during the establishment of a positive " tamponade test" in the management of postpartum haemorrhage. BJOG. 2010;117(3):295-303.

32. Ortega-Castillo VMJ, Espino and Sosa S, Herrerias-Canedo T. Control of obstetric hemorrhage with Bakri balloon. Ginecol Obstet Mex. 2013;81(8):435-39.

33. Condous GS, Arulkumarah S, Symonds I, et al. The " tamponade test" in the management of massive postpartum hemorrhage. Obstet Gynecol. 2003;101:767-72.

34. Frenzel D, Condous GS, Papageorghiou AT, et al. The use of " tamponade test" to stop massive obstetric haemorrhage in placenta accreta. BJOG. 2005; 112:676-7. 